\title{
An Empirical Study on the Correlation between CSI Bond Index and Enterprise Commodity Price Index
}

\author{
Qu Yí, Yao Yuduob ${ }^{\mathrm{b}}$, Zhou Lina \\ Harbin Vocational College of Science and Technology, Harbin, China 150300 \\ aemail: 26444806@qq.com, bemail: YaoYuduo@hrbkjzy.com, cemail: ZhouLina@hrbkjzy.com
}

Keywords: China Securities Bond Index; CGPI; Correlation; Granger causality test

\begin{abstract}
The two represent the enterprise financing side, one represents the production terminal of the enterprise. This paper mainly wants to study the relationship between the two and the influence on the production activities. In this paper, we have selected representative CSI syndromes index and the general index of commodity price index in the two indices, and carried out the validity test according to the monthly data of 10 years from 2007 to 2016, Granger causality Inspection, VAR model and so on. After the empirical test, it is related and positive correlation, and it is the reason why the CSI bond index is the enterprise commodity price index through Granger causality test. So that the central bank in the application of enterprise commodity price index to predict and control inflation when the CSI bond index can also be some fluctuations in the enterprise commodity price index to make a forecast, and to make the relevant macroeconomic regulation and control.
\end{abstract}

\section{Introduction}

Since twentieth Century, the bond market in China has been developing rapidly. The issuance of bonds, financial bonds, corporate bonds and other bonds has increased year by year. The total turnover of bonds is also higher than one year. The total turnover of national bonds in 2015 is 130 trillion and 921 billion 903 million yuan, compared with the total volume of 2014 national bonds of 93 trillion and 518 billion 745 million. The yuan has grown by about $40 \%$. This growth rate is 3 percentage points higher than the 2014 growth rate of $37.87 \%$ in 2013 . The bond index is an indicator system that can reflect the overall dynamic situation of the bond market price. The origin time of the bond index has been over 30 years ago, but the related research and application of the bond index are few. The initial development of the bond index is similar to the stock index, only as a tool to observe the market volatility and market, and is not given the characteristics that can be invested. Interest rate volatility in the 70s and 80s last century has experienced a dramatic increase in roller coaster and a sharp drop in the following 90 years, and a variety of bond portfolios have also undergone dramatic fluctuations, and investors have set up bond portfolios and corresponding indices to effectively control portfolio returns and stabilize market volatility. Relative risk. It is precisely because of these backgrounds that the bond index has a new attribute -- investability, and at the same time, it promotes the leap of passive investment concept to the new concept. Today, the structure of the bond market has changed a lot, its products are also constantly enriched, and the investors have a deeper understanding and understanding of the risk at the present stage, all of which make the CSI bond index more easily responsive to the dynamics of financial investment.

\section{Empirical analysis}

In this paper, we use the ADF test to test the unit root stationarity of the original data. It is well known that most of the financial data are not stationary time series, and we need to do some processing to make them a stationary time series and then establish the regression model of the equation, so that the error caused by the data is not stable. Generally speaking, the variables involved in the macro-economy may be the time series of non-stationary relations. In order to avoid these 
unprocessed data, it is necessary to test the stability of these variables in order to avoid the effectiveness of the analysis results. After cointegration test, the variables are generally analyzed with the same order, and then the ADF method can be used to test the unit root. Figure 4-1 shows that the original sequence of each index has not been tested, which indicates that the variable is a nonstationary sequence. As shown in Table 1:

Table 1 variable ADF test

\begin{tabular}{llll}
\hline Variable & ADF statistics & probability & conclusion \\
\hline LBI & 3.369218 & 1.000000 & Nonstationary \\
LCGPI & -1.043640 & 0.7358 & Nonstationary \\
\hline
\end{tabular}

After dealing with the technology of first order difference test, the variables can reach a stable state. The results of the test are shown in Table 2. From the table, we can see that the first order difference between LBI and LCGPI can be tested on ADF at a very significant level. Therefore, the two indices obtained from natural logarithms are all first order single integer sequences.

Table 2 First order ADF test of variables

\begin{tabular}{llll}
\hline Variabl & ADF & & conclusion \\
$\mathrm{e}$ & statistics & probability & \\
\hline LBI & -3.726278 & 0.0048 & stationary \\
LCGPI & -4.039982 & 0.0018 & stationary \\
\hline
\end{tabular}

The original hypothesis (H0) of ADF unit root test indicates that the original sequence is unstable, while the alternative hypothesis (H1) indicates that the original sequence is stationary. If it is verified that the detection value of the ADF is higher than the critical value of the result used for judgment, then the original hypothesis (H0) is accepted, that is, this sequence is nonstationary; if the ADF detection value obtained through the test can not be higher than the critical value of the decision, then the original assumption that the $\mathrm{H} 0$ is not accepted, it should be chosen to accept the optional leave at this time. Set $\mathrm{H} 1$ to show that the sequence is stationary.

As shown in Table 3, the discovery order 2 is the best and significant lag order determined by most criteria, so we select the 1 order as the optimal delay order of the later model.

Table 3 VAR lag order confirmation table

\begin{tabular}{lllllll}
\hline Lag & LogL & LR & FPE & AIC & SC & HQ \\
\hline 0 & 26.50592 & NA & $3.13 E-06$ & -1.323878 & -1.14431 & -1.2626 \\
1 & 210.3878 & 313.6809 & $1.62 \mathrm{E}-10$ & -11.19928 & $-10.30142 *$ & -10.8931 \\
2 & 235.2259 & $36.52655^{*}$ & $1.01 \mathrm{e}-10 *$ & $-11.71917 *$ & -10.10302 & $-11.16802 *$ \\
3 & 247.8039 & 15.53751 & $1.38 \mathrm{E}-10$ & -11.51787 & -9.183441 & -10.7218 \\
\hline
\end{tabular}

* the optimal lag period selected by the criterion

We choose the 2 order as the standard and then do the Johansen test. The results are shown in Table 4: 
Table 4 Johansen test result table

\begin{tabular}{lllll}
\hline $\begin{array}{l}\text { Zero } \\
\text { hypothetical } \\
\text { cointegration } \\
\text { vector number }\end{array}$ & $\begin{array}{l}\text { Characteristic } \\
\text { root }\end{array}$ & $\begin{array}{l}\text { Maximal } \\
\text { Eigenvalue } \\
\text { Statistic }\end{array}$ & $\begin{array}{l}5 \% \text { critical } \\
\text { value }\end{array}$ & probability \\
\hline None * & 0.110137 & 17.66595 & 15.49471 & 0.0232 \\
Less than one & 0.033722 & 4.013474 & 3.841466 & 0.0451 \\
Less than two & 0.110137 & 13.65248 & 14.26460 & 0.0623 \\
Less than three & 0.033722 & 4.013474 & 3.841466 & 0.0451 \\
\hline
\end{tabular}

* indicates a significant level of 5\%

In the values obtained after the Johansen maximum eigenvalue detection, we can see that there is a long-term stable cointegration relationship between the two variables of LBI and LCGPI at the standard level of $5 \%$, so we establish a two correlation model, which refer to the lower table 5 of the cointegration coefficient.

Table 5 cointegration coefficient of standardization

\begin{tabular}{cc}
\hline LBI & LCGPI \\
\hline \multirow{2}{*}{1.000000} & -1.360861 \\
& $(0.40087)$ \\
\hline
\end{tabular}

Through cointegration test, we obtain such an equation, which shows that there is a long-term stable and balanced relationship between the two parties of the Sino bond index and the enterprise commodity price index, and the model is established as follows:

$$
L C G P I=\beta+1.360861 L B I+\mu
$$

$$
\text { (0.40087) }
$$

The equation shows that there is a positive correlation between the CSI bond index and the corporate price index. After the Johansen test, in order to more determine the stability of the model, we use the AR root chart test to further confirm the stability of the equation, and the result is table 6 .

Table 6 cointegration AR validation

\begin{tabular}{cc}
\hline root & coefficient \\
\hline 0.992444 & 0.992444 \\
$0.903300-0.229140 \mathrm{i}$ & 0.93191 \\
$0.903300+0.229140 \mathrm{i}$ & 0.93191 \\
$0.687626-0.409893 \mathrm{i}$ & 0.800426 \\
$0.687626+0.409893 \mathrm{i}$ & 0.800426 \\
$-0.029068-0.196794 \mathrm{i}$ & 0.198939 \\
$-0.029068+0.196794 \mathrm{i}$ & 0.198939 \\
0.107347 & 0.107347 \\
\hline
\end{tabular}


If the absolute value of the inverse of the eigenvalue of the AR model is less than 1 , it shows that it exists within the unit circle, which can indicate that the model is stable, and otherwise the model is unstable. As shown in Table 6, we can see that there are altogether PN AP roots (P is lagged order, $\mathrm{N}$ is the number of endogenous variables in t phase), and this case consists of 8 AR unit roots. The absolute values of the root detection values of these 8 units are all within 1, so the model is stable.

Figure 3 below is an impulse response diagram for the period of the index of the bond index and the index of the enterprise commodity price index, which is 30. It can be seen that after a positive impact on the CSI index in this period, it has been a positive impact on the enterprise commodity price index in the 30 period, with a smaller impact, close to 0 . At the same time, the added value of the bond index has a positive impact on the enterprise commodity price index, when the impact of the third phase is affected. The largest, then from the seventeenth phase to the beginning of stability, it can be seen that this impact has a significant positive effect and has a very long lasting effect.

\section{Conclusion}

The financing problem of small and medium enterprises and the rapid growth of the price index are all the economic problems that can not be ignored. With the progress of the society and the rapid development of the economy, our country has paid more and more attention to the CPI and the commodity price index of the two issues. These two indexes also play an increasingly important role in the people's Bank of China in adopting corresponding monetary policies to solve macroeconomic problems. According to the empirical analysis of this paper, although the two indices such as CPI and CPI seem unrelated, it is not difficult to find a mechanism that reflects the financing of enterprises and the other is the wholesale price of enterprises. The price index at the end of the day. To a great extent, the CSI can represent some fluctuations in the financing of our enterprises before the production activities, and the commodity price index of the enterprise is taken from the wholesale price of the enterprise after the end of the production link. The reasonable use of the correlation between the two can not only help the enterprises to make better financing and pricing. It can also give instructions to the central bank for further macro financial control.

\section{Acknowledgements}

Heilongjiang Province ordinary undergraduate colleges and universities young innovative talents training plan. Research on the allocation efficiency of financial resources in China from the perspective of contract theory (item number: UNPYSCT-2016058), host Zhong Shen.

Heilongjiang Education Science 12th Five-Year plan topic. Research on "effective training of skilled talents in Higher Vocational Colleges" (item number: ZJC1215003), host Qu Yi

Study on the Countermeasures of Vocational Education Collectivization - Taking Harbin Modern Service Vocational Education Group as an example numbering the planning subject of the Provincial Education Department of the "13th Five-Year" program of education science of Heilongjiang Province. (Item number: ZJC1316055), host Zhu Jinghu.

\section{References}

[1] Donald G.Paterson, Ronald A.Shearer.A history of prices in Canada, 1840-1871: a new wholesale price index[J].Canadian Journal of Economics/Revue canadienne d'économique,2004,36(1).

[2] Irfan Civcir. Before the fall, Was the Turkish Lira Overvalued? [J].Eastern European Economics, 2003, 41(2).

[3] Yilmaz Akdi, Hakan Berument, Seyit MÜmin Cilasun, Hasan Olgun. The relationship between different price indexes: A set of evidence from inflation targeting countries [J].Statistical Journal of the United Nations Economic Commission for Europe, 2007, 23(2, 3). 
[4] Aviral Kumar Tiwari. Causality between wholesale price and consumer price indices in India: An empirical investigation in the frequency domain [J]. Indian Growth and Development Review, 2012, $5(2)$.

[5] Kuang Xiaoping, dry Lin. An Empirical Study on the correlation between inflation and stock prices and housing prices in China [J]. Shandong Social Sciences, 2012 (10):139-142. 